\title{
Chromoblastomycosis after a leech bite complicated by myiasis: a case report
}

\author{
Günther Slesak ${ }^{1,2^{*}}$, Saythong Inthalad ${ }^{1,3}$, Michel Strobel ${ }^{4}$, Matthias Marschal ${ }^{5}$, Martin JR Hall ${ }^{6}$, Paul N Newton ${ }^{7,8}$
}

\begin{abstract}
Background: Chromoblastomycosis is a chronic mycotic infection, most common in the tropics and subtropics, following traumatic fungal implantation.

Case presentation: A 72 year-old farmer was admitted to Luang Namtha Provincial Hospital, northern Laos, with a growth on the left lower leg which began 1 week after a forefoot leech bite 10 years previously. He presented with a cauliflower-like mass and plaque-like lesions on his lower leg/foot and cellulitis with a purulent tender swelling of his left heel. Twenty-two Chrysomya bezziana larvae were extracted from his heel. PCR of a biopsy of a left lower leg nodule demonstrated Fonsecaea pedrosoi, monophora, or F. nubica. He was successfully treated with long term terbinafin plus itraconazole pulse-therapy and local debridement.
\end{abstract}

Conclusions: Chromoblastomycosis is reported for the first time from Laos. It carries the danger of bacterial and myiasis superinfection. Leech bites may facilitate infection.

\section{Background}

Chromoblastomycosis is a worldwide chronic infection of the skin and subcutaneous tissue, most commonly found in tropical and subtropical areas. It is mainly caused by the fungal genera Fonsecaea, Phialophora and Cladophialophora that are saprophytes in soil and plants [1-3]. Fonsecaea pedrosoi is the commonest agent found in tropical rain forests [1]. Infection occurs by traumatic cutaneous implantation of fungi [1], for example by skin abrasion from wood or thorns and rarely by an insect or leech bite $[4,5]$. The lower limbs are most commonly infected and the nodular and/or verrucous plaques can develop centripetal satellite lesions. The most frequent complication is bacterial secondary infection, but malignancies have also been recorded $[1,2,6]$. Diagnosis can be made by direct microscopic demonstration of pathognomonic brown sclerotic cells (also called fumagoid or muriform cells) in skin scrapings [1-3].

\section{Case Presentation}

An otherwise healthy 72-year-old Khmu farmer was admitted in August 2009 at Luang Namtha Provincial Hospital, northern Lao PDR (Laos), with a painful

\footnotetext{
* Correspondence: guentherslesak@web.de

${ }^{1}$ SFE Medical Project, Luang Namtha, Lao PDR

Full list of author information is available at the end of the article
}

massive growth on his lower left leg, preventing walking. A red nodule developed one week after a leech bite on the dorsum of the left foot and over ten years, this painless, non-itchy growth spread up to his knee. Three days before admission he developed a painful left ankle with discharge from his heel. On examination he was oriented, afebrile (axillary $37.5^{\circ} \mathrm{C}$ ) with normal vital signs but cauliflower-like masses and several centripetally verrucous oval plaque-like lesions on his left lower leg and foot, with erythema and warmth and a purulent ulcerative very tender swelling of his left heel (Figure 1 and 2).

He was thought initially to have leprosy or skin cancer, but skin scrapings from the left lower leg lesions revealed typical brownish, round, thick-walled, multiseptate sclerotic cells in a wet film, confirmed with the $10 \%$ potassium hydroxide technique [1-3] (Figure 3 and 4). Left lower leg and foot radiographs showed no evidence of bone involvement. He was treated with oral cloxacillin and metronidazole for 1 week, followed by cotrimoxazole, and local iodine-based antiseptics. Bacterial culture of wound discharge grew Escherichia coli susceptible to co-trimoxazole by disc diffusion testing (according to CLSI guidelines [7]). During wound dressing on day 3, 22 maggots (fly larvae) were discovered in the heel wound (Figure 5, Additional file 1) and
C Biomed Central

C 2011 Slesak et al; licensee BioMed Central Ltd. This is an Open Access article distributed under the terms of the Creative Commons Attribution License (http://creativecommons.org/licenses/by/2.0), which permits unrestricted use, distribution, and reproduction in any medium, provided the original work is properly cited. 


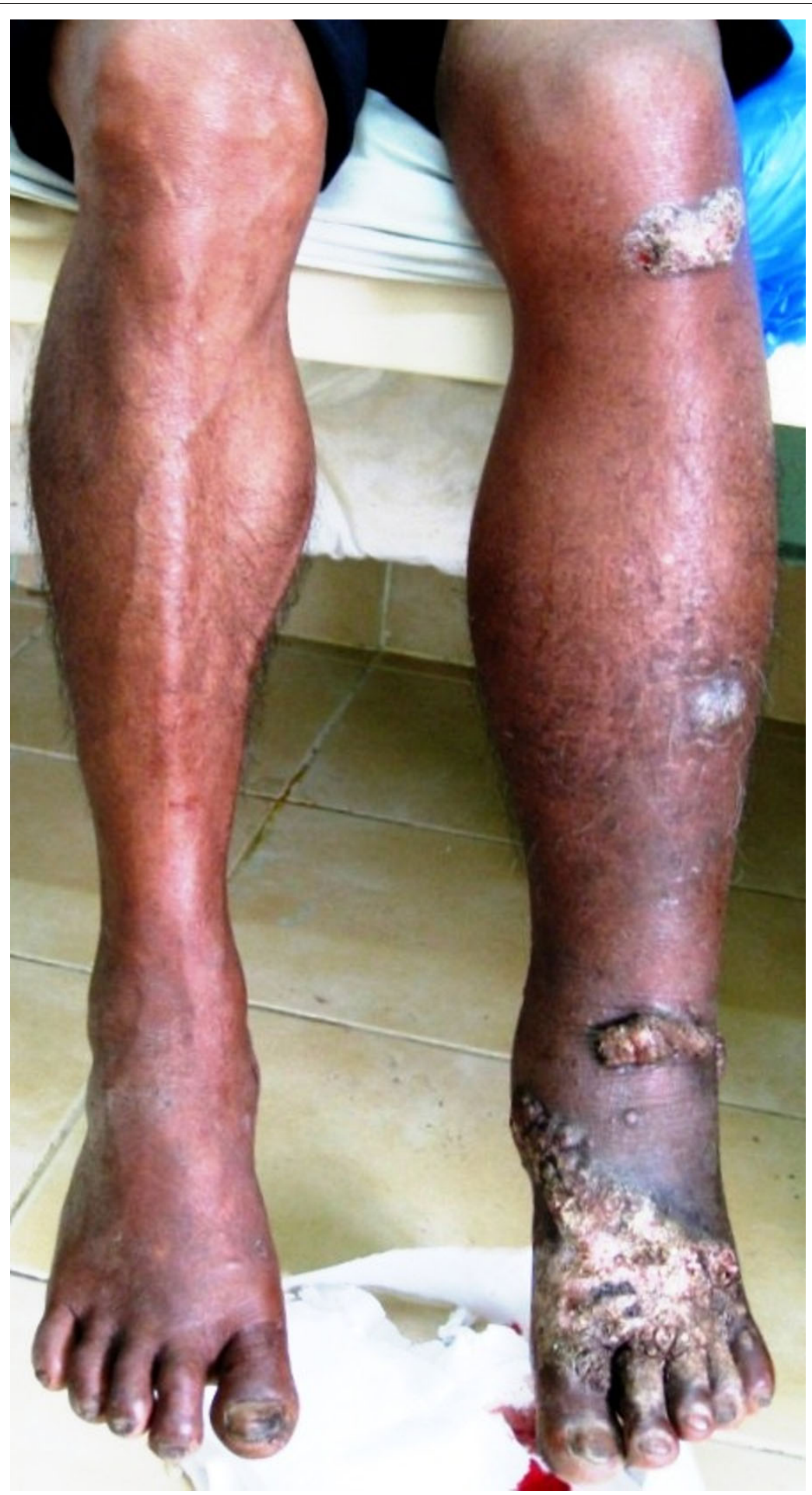

Figure 1 Lower legs of the patient at presentation with typical lesions on his left foot that spread centripetally up to his knee.

identified as third instar larvae of the Old World screwworm fly, Chrysomya bezziana (Diptera: Calliphoridae) [8]. Due to the pathognomonic microscopic findings of sclerotic cells he was diagnosed with chromoblastomycosis and started on itraconazole $400 \mathrm{mg} / \mathrm{d}$ monthly pulse therapy [5] on day 18 and a surgical debridement of all skin lesions was performed on day 21 .

In order to confirm the diagnosis, and as fungal cultures were not available in Laos, identification by PCR was attempted at Tübingen from heated and ethanol-treated 


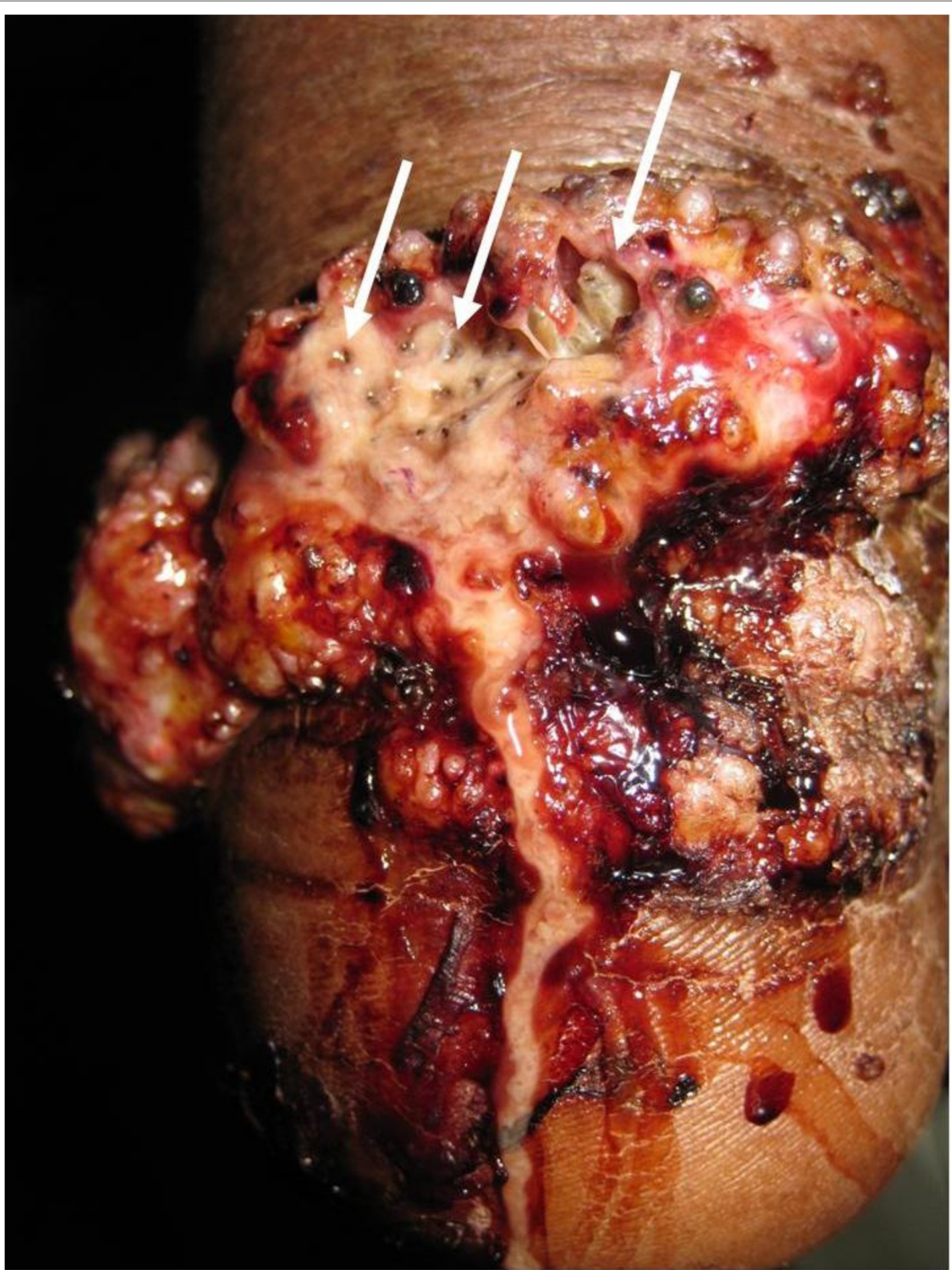

Figure 2 Patient's heel with groups of deeply burrowed larvae and their black caudal ends.

tissue. DNA extraction was performed from each of three tissue samples of about $3 \mathrm{~mm}$ in diameter from the patient's lower leg. Fungal DNA was amplified with two different PCR-protocols, using primers of the internal transcribed spacer (ITS) 1 and 4 region $[9,10]$ and the conserved $18 \mathrm{~S}$ subunit of the rRNA gene [11] with $2.5 \mu \mathrm{l}$ of DNA-extract applied in each PCR reaction. PCR-products were subsequently sequenced as described [11] and compared with Basic Local Alignment Search Tool (BLAST). PCR using ITS primers 


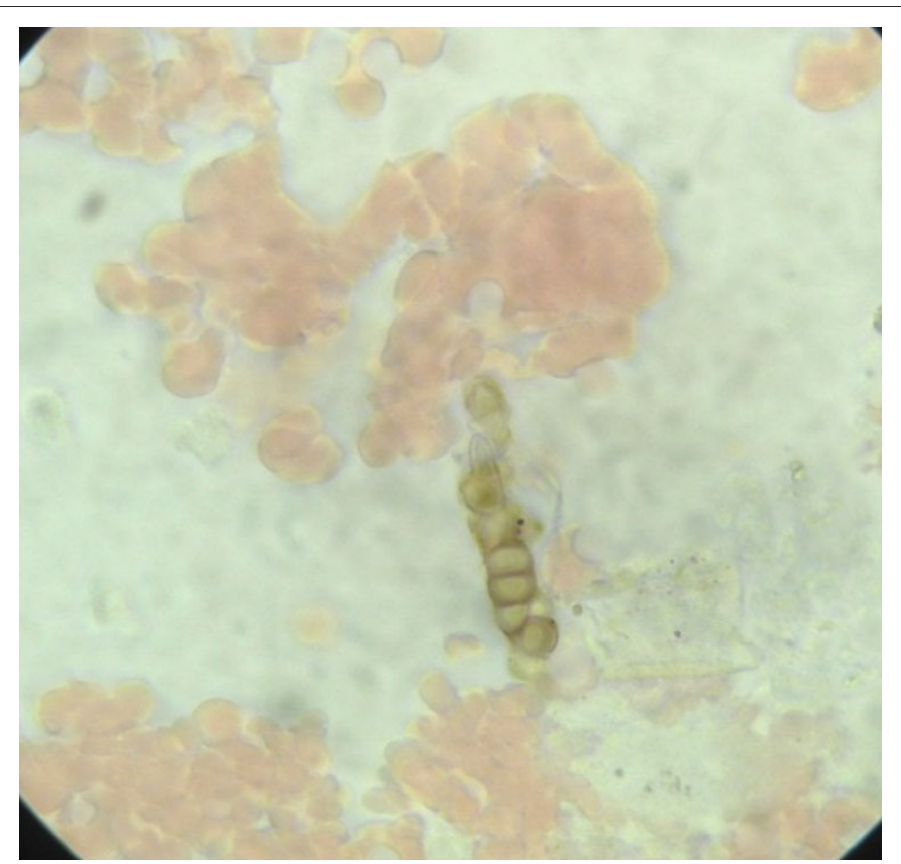

Figure 3 Characteristic brownish sclerotic cells in skin scrapings (100x objective with oil, wet film).

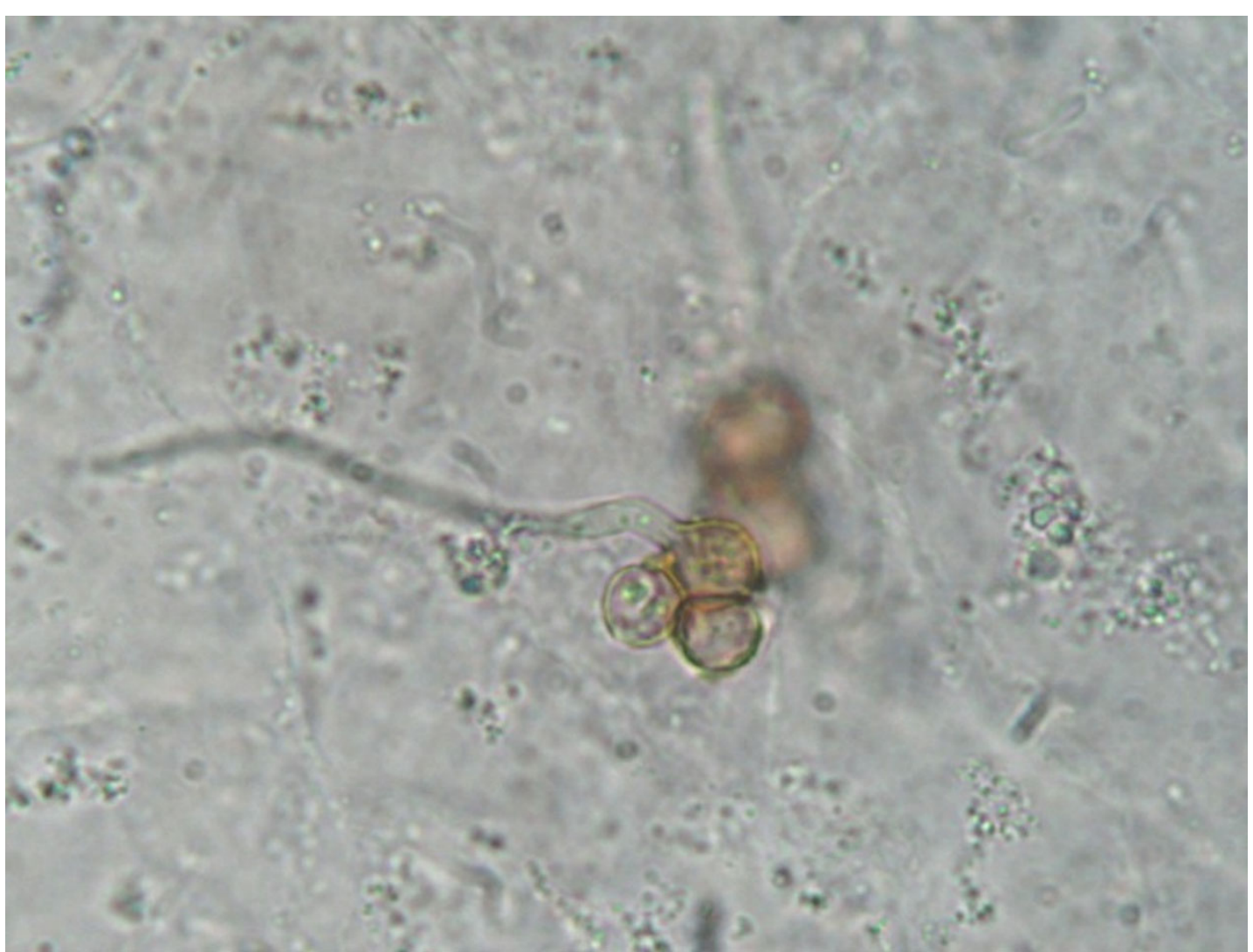

Figure 4 Sclerotic cells with hyphae (10\% potassium hydroxide technique) 


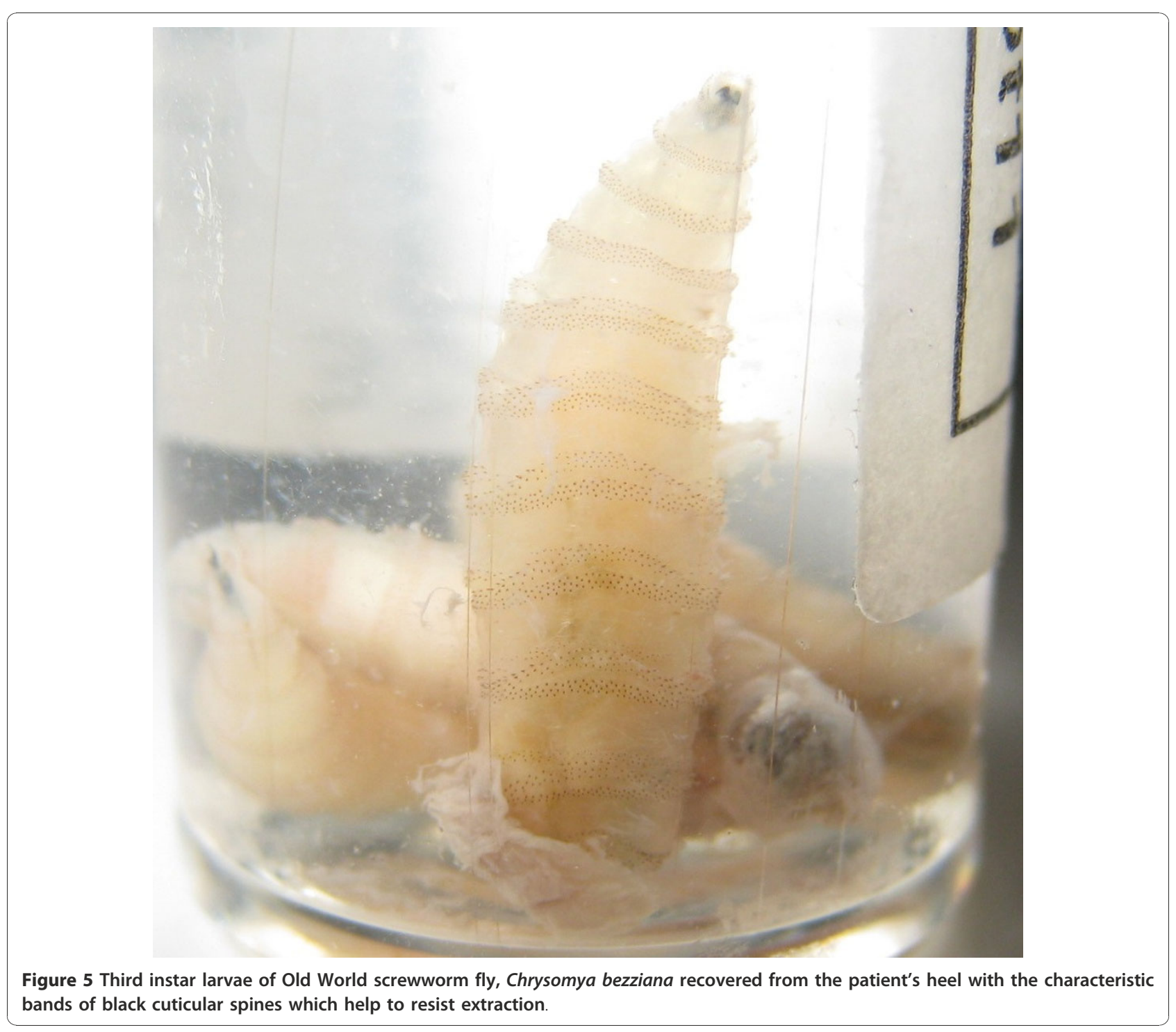

remained negative in all 3 samples, whereas $18 \mathrm{~S}$ rRNAPCR was positive in one of the 3 samples. Subsequent sequencing revealed $100 \%$ similarity with Fonsecaea pedrosoi, monophora, and F. nubica. The sequence was published in GenBank (accession number HQ616145).

After 4 months, oral terbinafin $(500 \mathrm{mg} /$ day, later $750 \mathrm{mg} /$ day) for 9 months was added. Local terbinafin ointment was also applied for 6 months. The patient's left lower leg and foot healed without lesions but with some residual swelling (Figure 6).

\section{Discussion}

Chromoblastomycosis has been reported from neighbouring Thailand and China [5,12], and it is likely to be endemic in Laos. Its slow growth and variable appearance may result in confusion with skin cancer, eczema, psoriasis, or leprosy, as in our patient. Direct microscopic identification of muriform/sclerotic cells is diagnostic [1-3] but doctors have to be aware of this differential diagnosis. Treatment remains challenging, especially in financially-poor countries. Antifungals needed to be given for at least 6-12 months, often combined with physical treatments such as surgery, cryotherapy and thermotherapy. Cure rates range from $15 \%$ to $80 \%$ [1]. Despite being the most common aetiological agent, F. pedrosoi appears to be less sensitive to antifungal therapy than either $C$. carrionii or $P$. verru$\cos a[1,2]$. However, terbinafin has shown high tolerability and efficacy especially against $F$. pedrosoi, even in imidazole-refractory cases [13] and dual therapy with itraconazole and terbinafin is recommended [1]. Which species of Fonsecaea was responsible remains unclear in 


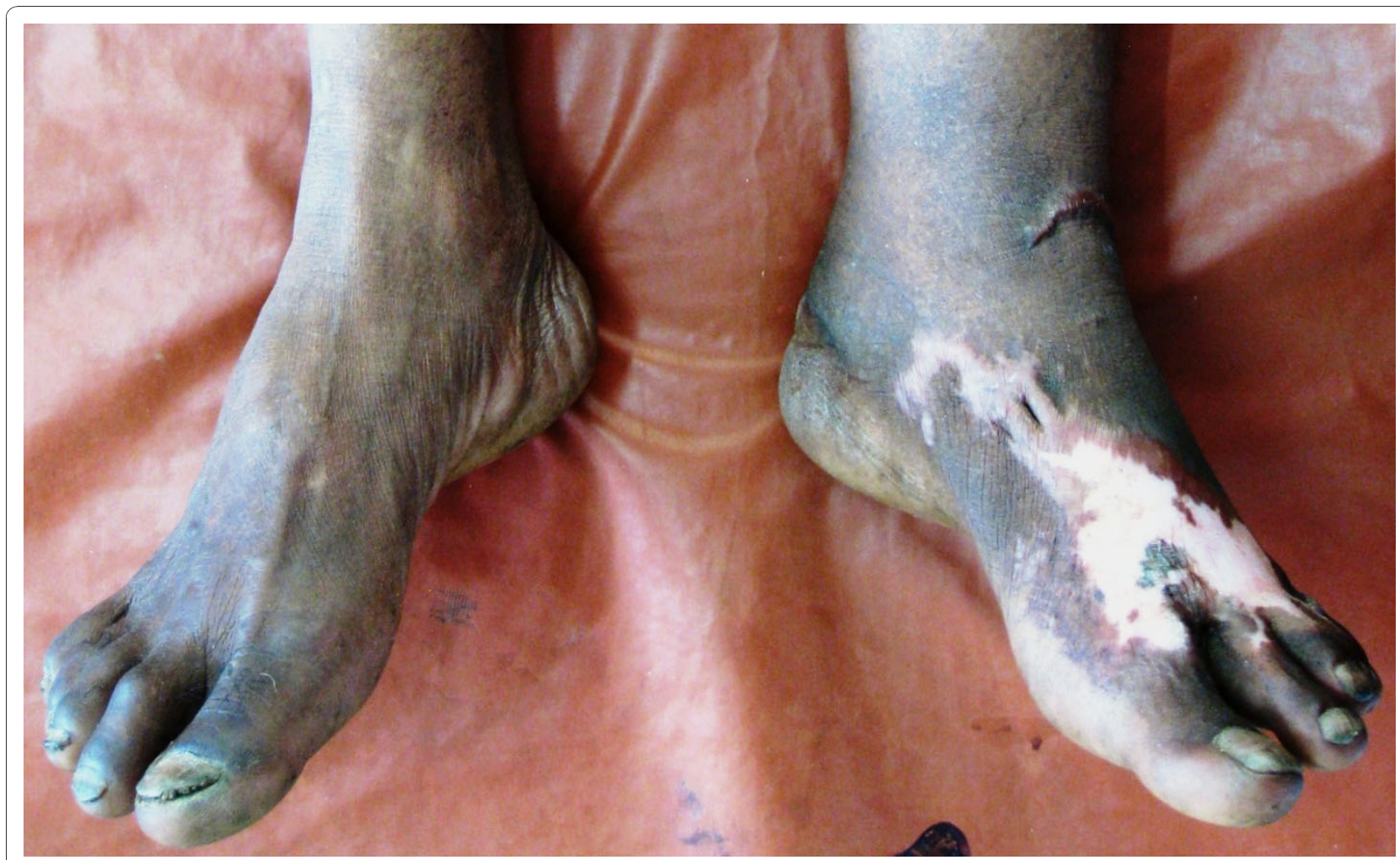

Figure 6 Healed skin lesions 8 months after initiation of antifungal treatment and surgical debridement.

our patient. The gene sequence analysis using $18 \mathrm{~S}$ primers, in contrast to ITS primers, which have been used for Fonsecaea species identification in pure cultures [14-16], cannot distinguish between Fonsecaea pedrosoi, F. monophora and F. nubica [17]. The finding that only one sample was positive with $18 \mathrm{~S}$ primers might be due to a very low fungal load or an alteration during the sample processing and transport from remote northern Laos. PCR with $18 \mathrm{~S}$ primers may have a higher sensitivity for the detection of Fonsecaea spp. from biopsy material compared to ITS primers, however, PCR diagnosis of Fonsecaea spp. is not yet standardized.

It is possible that the patient acquired the infection via the leech bite or subsequently through the wound. The injection of platelet inhibitors during leech bites [18] might impair the local skin immunity increasing the risk for fungal infections. The coagulation system overlaps with the immune system and many acutephase proteins of inflammation are also involved in the coagulation process. Platelet microbiocidal proteins and konocidins have shown to exert strong efficacy against bacteria and fungi [19]. To our knowledge this is the second report of chromoblastomycosis associated with a leech bite [5]. Since leeches are typically found in humid tropical areas, as is chromoblastomycosis, there might be an important but overlooked association. Leech bites have been associated with Aeromonas hydrophilia infections, complicating $2.4 \%$ to $20 \%$ of medical leech therapies [20], but might also be involved in the pathogenesis of other tropical soil-related infections, such as Chromobacterium violaceum septicaemia [21]. Ingested blood in leeches' digestive tract can contain various pathogens, including HIV and hepatitis B, that, although unproven, could be re-injected into another host by regurgitation during the manipulation of leech removal [22].

Bacterial superinfection is a relatively common complication of chromoblastomycosis [1,2] but myiasis does not appear to have been reported. Cochliomyia hominivorax, Chrysomya bezziana, and Wohlfahrtia magnifica are the most common flies worldwide causing human wound myiasis. Chrysomya bezziana is the most common cause in India and Southeast Asia [23]. Although scientific evidence from Laos is scarce, old clinical descriptions indicate that myiasis has been a common poverty-related complication of neglected wounds in remote areas of Laos [24]. Massive tissue destruction, bone erosion, and death can occur from infestation by Old World screwworm larvae [23]. Our patient had only three of the reported predisposing factors for wound 
myiasis including advanced age, poor social condition and hygiene, but did not have diabetes, vascular occlusive disease, alcoholism, mental/psychiatric illness, or physical disability [23]. However, the skin lesions of chromoblastomycosis could facilitate fly eggs deposition and might represent another risk factor for human wound myiasis. Although a potentially serious complication, the larval infestation and associated pain had the benefit here of prompting our patient to seek medical attention, which led to the root cause of his ten-year condition being successfully diagnosed and treated.

\section{Conclusions}

Chromoblastomycosis is reported for the first time from Laos and should be considered in the differential diagnosis of chronic skin diseases. Leech bites might facilitate infection and bacterial superinfection and myiasis may occur.

\section{Consent}

Written informed consent was obtained from the patient for publication of this case report including pictures and video.

\section{Additional material}

Additional file 1: Videoclip showing perpendicular scraping movements of maggots in the patient's very tender heel that initially were overlooked

\begin{abstract}
Acknowledgements
We thank the NGO SFE for the financial and organizational support of the patient's treatment and follow-up, and the Wellcome Trust of Great Britain for support of the microbiology testing and specimen transport. We are very grateful to Stephanie Richt and Mariola Gwozdz (Interfakultäres Institut für Mikrobiologie und Infektionsmedizin Tübingen, Germany) who performed the fungal PCR with subsequent sequence analysis, the NGO Direct Relief International, especially Matt MacCalla, for the rapid assistance in obtaining terbinafin, Dr Rattanaphone Phetsouvanh and Dr Mayfong Mayxay and all staff of the Microbiology Laboratory, Mahosot Hospital and Cheryl Whitehorn of the London School of Hygiene and Tropical Medicine for assistance. PNN is supported by Wellcome Trust of Great Britain.
\end{abstract}

\section{Author details}

${ }^{1}$ SFE Medical Project, Luang Namtha, Lao PDR. ${ }^{2}$ Tropenklinik Paul-LechlerKrankenhaus, 72076 Tübingen, Germany. ${ }^{3}$ Luang Namtha Provincial Hospital, Luang Namtha, Lao PDR. ${ }^{4}$ Institut de la Francophonie pour la Médecine Tropicale, Vientiane, Lao PDR. ${ }^{5}$ Interfakultäres Institut für Mikrobiologie und Infektionsmedizin, Tübingen, Germany. ${ }^{6}$ Department of Entomology, Natural History Museum, Cromwell Road, London, UK. ${ }^{7}$ Wellcome Trust-Mahosot Hospital-Oxford Tropical Medicine Research Collaboration, Microbiology Laboratory, Mahosot Hospital, Vientiane, Lao PDR. ${ }^{8}$ Centre for Clinical Vaccinology and Tropical Medicine, Churchill Hospital, University of Oxford, Oxford, England, UK.

\section{Authors' contributions}

GS and SI were the attending physicians who looked after the patient. MS helped with the microscopic diagnosis from skin specimen. MH identified the larvae. GS, SI, and PNN wrote the first draft and all authors revised it. All authors have read and approved the final version.

\section{Competing interests}

The authors declare that they have no competing interests.

Received: 2 August 2010 Accepted: 12 January 2011

Published: 12 January 2011

\section{References}

1. Ameen M: Chromoblastomycosis: clinical presentation and management. Clin Exp Dermatol 2009, 34:849-854

2. Bonifaz A, Carrasco-Gerard E, Saúl A: Chromoblastomycosis: clinical and mycologic experience of 51 cases. Mycoses 2001, 44:1-7.

3. Queiroz-Telles F, Esterre P, Perez-Blanco M, Vitale RG, Salgado CG, Bonifaz A Chromoblastomycosis: an overview of clinical manifestations, diagnosis and treatment. Med Mycol 2009, 47:3-15.

4. Sauerteig E, Hernández R, Salfelder K, Bastidas C: Acute chromoblastomycosis provoked by an insect bite in an immunosuppressed patient. Mycoses 1998, 41:191-194.

5. Ungpakorn R, Reangchainam S: Pulse itraconazole $400 \mathrm{mg}$ daily in the treatment of chromoblastomycosis. Clin Exp Dermatol 2006, 31:245-247.

6. Minotto R, Bernardi CDV, Mallmann LF, Edelweiss MIA, Scroferneker ML: Chromoblastomycosis: a review of 100 cases in the state of Rio Grande do Sul, Brazil. J Am Acad Dermatol 2001, 44:585-592.

7. Clinical and Laboratory Standards Institute: Performance Standards for Antimicrobial Disk Susceptibility Tests; Approved Standard. . Tenth edition. Wayne, PA: Clinical and Laboratory Standards Institute; 2009, Approved Standard M02-A10.

8. Hall MJR: New World screwworm (Cochliomyia hominivorax) and Old World screwworm (Chrysomya bezziana). In Manual of Diagnostic Tests and Vaccines for Terrestrial Animals (mammals, birds and bees). Volume 1. Sixth edition. OiE, World Organisation for Animal Health. Paris, France; 2008:265-275 [http://www.oie.int/eng/Normes/mmanual/2008/pdf/ 2.01.10_SCREWW.pdf], Chapter 2.1.10.

9. Loeffler J, Hebart H, Bialek R, Hagmeyer L, Schmidt D, Serey FP, Hartmann M, Eucker J, Einsele H: Contaminations occurring in fungal PCR assays. J Clin Microbiol 1999, 37:1200-1202.

10. Leinberger DM, Schumacher U, Autenrieth IB, Bachmann TT: Development of a DNA microarray for detection and identification of fungal pathogens involved in invasive mycoses. J Clin Microbiol 2005, 43:4943-53.

11. Einsele $H$, Hebart $H$, Roller $G$, Löffler J, Rothenhöfer I, Müller CA, Bowden RA, Van Burik JA, Engelhard D, Kanz L, Schumacher U: Detection and identification of fungal pathogens in blood by using molecular probes. J Clin Microbiol 1997, 35:1353-60.

12. Zhang J, Xi L, Lu C, Li X, Xie T, Zhang H, Xie Z, Sybren DH: Successful treatment for chromoblastomycosis caused by Fonsecaea monophora: a report of three cases in Guangdong, China. Mycoses 2008, 52:176-181.

13. Esterre P, Inzan CK, Ramarcel ER, Andriantsimahavandy A, Ratsioharana M, Pecarrere $J$, Roig P: Treatment of chromomycosis with terbinafine: preliminary results of an open pilot study. Br J Dermatol 1996, 134(Suppl 46):33-36

14. Xi L, Sun J, Lu C, Liu H, Xie Z, Fukushima K, Takizawa K, Najafzadeh MJ, De Hoog GS: Molecular diversity of Fonsecaea (Chaetothyriales) causing chromoblastomycosis in southern China. Med Mycol 2009, 47:27-33.

15. De Andrade TS, Cury AE, de Castro LG, Hirata MH, Hirata RD: Rapid identification of Fonsecaea by duplex polymerase chain reaction in isolates from patients with chromoblastomycosis. Diagn Microbiol Infect Dis 2007, 57:267-272.

16. Sun J, Najafzadeh MJ, Vicente $V$, Xi L, de Hoog GS: Rapid detection of pathogenic fungi using loop-mediated isothermal amplification, exemplified by Fonsecaea agents of chromoblastomycosis. J Microbiol Methods 2010, 80:19-24.

17. Najafzadeh MJ, Sun J, Vicente V, Xi L, van den Ende AH, de Hoog GS: Fonsecaea nubica sp. nov a new agent of human chromoblastomycosis revealed using molecular data. Med Mycol 2010, 48:800-6.

18. White TC, Berny MA, Robinson DK, Yin H, DeGrado WF, Hanson SR, McCarty OJT: The leech product saratin is a potent inhibitor of platelet integrin $\alpha_{2} \beta_{1}$ and von Willebrand factor binding to collagen. FEBS J 2007, 274:1481-1491.

19. Yeaman MR: Platelets in defense against bacterial pathogens. Cell Mol Life Sci 2010, 67:525-544. 
20. Ardehali B, Hand K, Nduka C, Holmes A, Wood S: Delayed leech-borne infection with Aeromonas hydrophilia in escharotic flap wound. J Plast Reconstr Aesthet Surg 2006, 59:94-95.

21. Slesak G, Douangdala P, Inthalad S, Silisouk J, Vongsouvath M, Sengduangphachanh A, Moore CE, Mayxay M, Matsuoka H, Newton PN: Fatal Chromobacterium violaceum septicaemia in northern Laos, a modified oxidase test and post-mortem forensic family G6PD analysis. Ann Clin Microbiol Antimicrob 2009, 8:24.

22. Nehili M, Ilk C, Mehlhorn H, Ruhnau K, Dick W, Njayou M: Experiments on the possible role of leeches as vectors of animal and human pathogens: a light and electron microscopy study. Parasitol Res 1994, 80:277-290.

23. McGraw TA, Turiansky GW: Cutaneous myiasis. J Am Acad Dermatol 2008, 58:907-926.

24. Dooley TA: The edge of tomorrow. New York: Farrar, Straus \& Cudahy; 1958.

\section{Pre-publication history}

The pre-publication history for this paper can be accessed here: http://www.biomedcentral.com/1471-2334/11/14/prepub

doi:10.1186/1471-2334-11-14

Cite this article as: Slesak et al: Chromoblastomycosis after a leech bite complicated by myiasis: a case report. BMC Infectious Diseases 2011 11:14.

\section{Submit your next manuscript to BioMed Central} and take full advantage of:

- Convenient online submission

- Thorough peer review

- No space constraints or color figure charges

- Immediate publication on acceptance

- Inclusion in PubMed, CAS, Scopus and Google Scholar

- Research which is freely available for redistribution

Submit your manuscript at www.biomedcentral.com/submit 